\title{
Information Retrieval using Dynamic Decision Quadtree in Soil Database
}

\author{
A. Meenakshi ${ }^{*}$, P. Suganthi' ${ }^{2}$, R. Aghila ${ }^{2}$ and S. Nirmala ${ }^{2}$ \\ 'Department of Information Technology, K.L.N. College of Information Technology, Madurai - 630612, Tamil Nadu, \\ India; rajeshmeenakshi1@gmail.com \\ 2Department of Computer Science and Engineering, K.L.N. College of Information Technology, Madurai - 630612, \\ Tamil Nadu, India; suga.pathma@gmail.com, aghila25481@rediffmail.com, nirmalasme@gmail.com
}

\begin{abstract}
Background: Data volume with respect to modern systems has been growing outwardly at a rapid rate. The systems also face a tough task of frequent re-scanning of the large datasets stored because of the updation process. Frequent rescanning, updation and large corpus data leads to having larger retrieval time and decreased efficiency. Hence, the data retrieved by automated systems may not be efficient and accurate. Knowledge Based System using Dynamic decision Quad tree is employed in this paper. The Quad trees designed in this chapter helps in retrieving knowledge about the suitable plants for the given kind of soil. Methods: The Quad trees designed in this paper helps in retrieving knowledge about the suitable plants for the given kind of soil. The Dynamic decision Quad tree is built using the knowledge and information given by Edaphologists and domain experts. The system is made of two modules, namely Dynamic Quad Tree construction module and information retrieval module. In the first module, the obtained data is transformed to a dynamic Quad tree based knowledge data structure. In the information retrieval module, knowledge retrieval is carried out with the help of constructed knowledge base (XML). Findings: Efficient techniques have been developed and tailored for solving complex soil datasets using data mining. The proposed scheme exploits clustering and dynamic decision tree based system for better storage in edaphology compared to existing systems. Dynamic decision quad trees are tailored to make best retrieval in soil databases. Applications: Assist Edaphologists and agricultural experts in obtaining the right crops/plants for the given soil characteristics.
\end{abstract}

Keywords: Data mining, Edaphology, Information Retrieval, Knowledge Extraction

\section{Introduction}

Data volume with respect to modern systems has been growing outwardly at a rapid rate ${ }^{1}$. The systems also face a tough task of frequent re-scanning of the large datasets stored because of the updation process. Frequent re-scanning, updation and large corpus data leads to having larger retrieval time and decreased efficiency. Hence, the data retrieved by automated systems may not be efficient and accurate. Knowledge Based System using Dynamic decision Quad tree is employed in this paper. The Dynamic decision Quad trees designed in the paper helps in retrieving knowledge about the suitable plants for the given kind of soil ${ }^{2,3}$. The Quad tree is built using the knowledge and information given by Edaphologists and domain experts ${ }^{4,5}$. The system is made of two modules, namely Dynamic decision Quad Tree construction module and information retrieval module. In the Quad tree module, obtained data is transformed to a dynamic Quad tree based knowledge data structure ${ }^{6}$. In the information retrieval module, plant names are retrieved based on the input soil characteristics by the user. When the query is posted by the user with input parameters it fetches the appropriate plants from the quad tree and gives decision supporting information which helps Edaphologists and agricultural experts from identifying the right crops/plants for the given soil characteristics. In this paper, effective knowledge retrieval is carried out with the aid of XML architecture and XML

*Author for correspondence 
tags. The system is designed for retrieving best plants for the input soil condition given by the user. The obtained results prove that the system has performed well by having good evaluation metric values.

A dynamic decision tree is a decision support tool that uses a tree-like graph or model of decisions and their possible consequences, including chance event outcomes, resource costs, and utility ${ }^{7,8}$. They are commonly used in operations research, specifically in decision analysis, to help identify a strategy most likely to reach a goal ${ }^{9,10}$.

Initially, the knowledge is stored in the relational database with the input from the Edaphologists ${ }^{11}$. Here, it comprises of two tables of which one contains the plant details and the other contains the soil description. The plant details table consists of plant names, geology and taxonomy corresponding to the plant ID. Figure 2 shows an example of plant table $P$ having attributes plant identification number $I$, name $\mathrm{Na}$, geology $\mathrm{Ge}$ and the taxonomy Ta. We can see that a plant can have multiple plant IDs and the geology and taxonomy vary accordingly. The description table contains the plant ID, depth and the description of the soil. It also has the values of various parameters like clay, silt, sand, $\mathrm{Ph}$, electrical conductivity, Calcium, Magnesium, Sodium, Potassium and Phosphorus Pent-oxide, Potassium Oxide ${ }^{12}$.

The soil characteristics for the plant ID changes with the depth and because of that, each plant ID has more than one soil characteristics attached to $\mathrm{it}^{12}$. Figure 3 gives an example of soil characteristics table $S$ having attributes of plant identification number $I$, depth $D$, description $G$, clay $C l$, silt $S l$, sand $S a$, hydrogen ion concentration $H$, electrical conductivity $E$, calcium $G a$, magnesium $M$, sodium $N$ s, potassium $P t$, phosphorous pent oxide $P h$ and potassium oxide $P o$.

The Data flow of the proposed work is given in Figure 4.The input information is transformed into clusters by using key values for every plant data. And also the list is prepared for same plant IDs. Once the clusters are formed then it is transformed into dynamic decision tree $^{13}$ as shown in Figure 1.

\section{Clustering and Dynamic Decision Tree Construction}

The combination of clustering and dynamic decision tree is used for storage as given in Table 1. By using serializable concept the soil characteristics given in Table 2 are

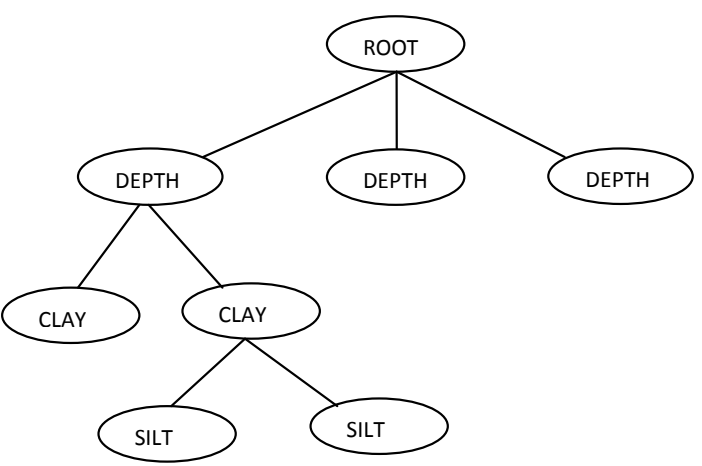

Figure 1. Sample dynamic decision tree.

\begin{tabular}{|c|c|c|c|}
\hline Id & name & Geology & Taxonomy \\
\hline 0001 & Prosophis juliflora, Cyprussp., Hariyali, C & & Fine, montmorillonitic, isohyperthermic, noncalcareous, Chromic Haplusterts \\
\hline 0003 & Palmyrah $\quad 0$ & Granite & Fine, mixed, isohyperthermic, noncalcreous, Typic Rhodustalfs \\
\hline 0017 & Eucalyptus, Palmyrah, Neem, Tamarind $L$ & Laterite & Fine, mixed, isohyperthermic, noncalcareous, Typic Haplustepts \\
\hline 0019 & Palmyrah, Neem & Granite & Clayey, mixed, isohyperthermic, noncalcareous, ithic Haplustepts \\
\hline 0021 & Palmyrah, Prosophis juliflora & Granite & Fine, mixed, isohyperthermic, noncalcareous, Typic Haplustalits \\
\hline 0023 & Neem, Palmyrah, Prosophis juliflora, Tas & & Loamy-over-sandy, mixed, isohyperthermic, noncalcareous, Typic Ustifluvents \\
\hline 0024 & Neem, Prosophis, Tamarind & Granite & Sandy, mixed, isohyperthermic, calcareous, Typic Ustorthents \\
\hline 0032 & Palmyrah & Sand & Sandy, mixed, isohyperthermic, noncalcareous, Aquic Ustipsamments \\
\hline 0035 & Neem, Palmyrah & Graite & Fine, mixed, isohyperthermic, calcareous, Calcic Haplustepts \\
\hline 0037 & Neem, Prosophis juliflora & Western Ghats & Fine, mixed, isohyperthermic, noncalcareous, Typic Haplustepts \\
\hline 0039 & Neem, Palmyrah, Tamarind & Granite & Fine, mixed, isohyperthermic, noncalcareous, Typic Haplustepts \\
\hline 0041 & Palmyrah, Neem, Accacia & Granite & Clayey-skeletal, mixed, isohyperthermic, noncalcareous, Typic Haplustepts \\
\hline 0042 & Ipomea, Thespesia populanea, Vagai & Clay & Fine, mixed, isohyperthermic, noncalcareous, Typic Rhodustalfs \\
\hline 0045 & Palmyrah, Neem, Prosophis juliflora & Granite & Loamy, mixed, isohyperthermic, noncalcareous, Uthic Ustorthents \\
\hline 0047 & Eucalyptus, Vagai & Laterite & Fine, mixed, isohyperthermic, noncalcoreous, Fluventic Haplustepts \\
\hline 0050 & Prosophis juliffora, Neem, Vetiver & Granite & Clayey-skeletal, mixed, isohyperthermic, noncalcareous, Ithic Ustorthents \\
\hline 0051 & Prosophis juliflora, Palmyrah & Granite & Fine-loamy, mixed, sohyperthermic, noncalcareous, Fluventic Haplustepts \\
\hline 0055 & Prosophis julifflor, Palmyrah, Tamarind $G$ & Granite & Fine-loamy, mixed, isohyperthermic, noncalcareous, Typic Haplustepts \\
\hline
\end{tabular}

Figure 2. The Plant table.

\begin{tabular}{|c|c|c|c|c|c|c|c|c|c|c|c|c|}
\hline id. & Depth & Desc1 $\quad$ C Clay & Silt & Sand & PH & $E C$. & $\mathrm{Ca}$. & - Ms & $\mathrm{Na}$. & $\mathrm{k}$. & 2205 . & - 120 . \\
\hline 0001 & 0.13 & Dark brown (10 YR $4 / 3$ ); sandy clay; $; 38.46$ & 15.84 & 45.70 & 8.30 & 1.30 & 11.80 & 4.10 & 3.59 & 0.40 & 10.00 & 120.00 \\
\hline 0001 & 13.65 & Dark grayish brown (10 VR $4 / 2$ ); sandy 41.92 & 18.07 & 40.01 & 8.90 & 1.50 & 13.87 & 4.30 & 4.07 & 0.46 & 10.00 & 80.00 \\
\hline 0001 & $65-184$ & Very dark gravish brown (10 YR 3/2) : 40.84 & 21.90 & 37.26 & 8.90 & 1.40 & 14.20 & 3.90 & 4.09 & 1.02 & & \\
\hline 0003 & 0.18 & $\operatorname{Red}(2.5 \mathrm{YR} 4 / 6)$; sandy clay loam; mo 24.60 & 15. & 60.2 & 7.36 & 0.04 & 8.0 & 1.5 & 0.68 & 0.32 & 29.45 & 228.00 \\
\hline 0003 & 18.42 & Red $(2.5$ YR $4 / 6)$; sandy clay loam; mo 25.60 & 16.8 & 57.60 & 7.11 & 0.04 & 10.0 & 20 & 0.73 & 0.35 & 27.37 & 376.00 \\
\hline 0003 & $42 \cdot 80$ & Dark yellowish brown (10 YR 4/6); cla 38.14 & 24.2 & 37.66 & 6.85 & 0.09 & 15.5 & 1.5 & 259 & 6.70 & 29.41 & 415.00 \\
\hline 0003 & $80-140$ & Dark yellowish brown $(10 \mathrm{YR} 4 / 6)$; cla 44.60 & & 29.80 & 6.81 & 0.08 & 18.5 & 1.5 & 4.25 & 4.62 & 15.60 & 425.00 \\
\hline 0017 & 0.10 & Dark yellowish brown (10 YR $4 / 4)$; sar 38.24 & 13.64 & 48.12 & 6.61 & 0.03 & 5.50 & 8.50 & 0.46 & 0.33 & 16.58 & 69.00 \\
\hline 0017 & $10-29$ & Brownish yellow (10 YR $6 / 6$ ) sandycl 36.92 & 14.06 & 49.02 & 7.02 & 0.03 & 5.50 & 5.00 & 0.51 & 0.25 & 9.50 & 42.00 \\
\hline 0017 & 29.57 & Brownish yellow (10 YR $6 / 6$ ); clay; mo 43.82 & 20.90 & 35.28 & 7.12 & 0.02 & 6.00 & 4.00 & 0.46 & 0.25 & 10.68 & 46.00 \\
\hline 0017 & 57.87 & Yellowish brown (10 YR 5/4); clay; mo 46.16 & 19.56 & 34.28 & 7.18 & 0.03 & 6.50 & 4.00 & 0.47 & 0.25 & 12.67 & 53.00 \\
\hline 0017 & $87-1000$ & Weathered parent & . & D & 0 & 0 & 0 & 0 & 0 & 0 & 0 & \\
\hline 0019 & 0.12 & Very dark grayish brown (10 YR 3/2); 44.60 & 20.24 & 35.16 & 8.19 & 0.07 & 31.00 & 6.50 & 0.36 & 0.28 & 20.78 & 122.00 \\
\hline 0019 & $12-25$ & Very dark grayish brown (10 YR 3/2): 488.40 & 21.26 & 30.34 & 8.33 & 0.05 & 32.00 & 8.00 & 0.38 & 0.08 & 19.82 & 141.00 \\
\hline 0019 & $25-39$ & Dark brown (10 YR 4/3); ;ravelly clar; 50.00 & 24.24 & 25.76 & 7.76 & 0.07 & 33.50 & 8.00 & 0.46 & 0.05 & 22.55 & 69.00 \\
\hline 0019 & $39 \cdot 1000$ & Weathered Granitic & 0 & 0 & 0 & 0 & 0 & 0 & 0 & 0 & 0 & \\
\hline 0021 & 0.18 & Reddish brown $(5 Y R 4 / 4)$; sandy clay 18.60 & 13.00 & 68.40 & 7.12 & 0.06 & 5.50 & 2.50 & 4.27 & 1.12 & 3.72 & 103.00 \\
\hline 0021 & $18-37$ & Reddish brown $(5$ YR 4/4); clay; mode 31.14 & 18.80 & 50.06 & 6.7 & 0.02 & 10.00 & 8.00 & 4.25 & 1.09 & 6.7 & 100.00 \\
\hline 0021 & 37.78 & Dark reddish brown (S YR $3 / 4$ ); clay; $\pi 34.60$ & 19.25 & 46.15 & 6.72 & 0.02 & 10.50 & 12.00 & 3.75 & 1.17 & 4.67 & 108.00 \\
\hline 0023 & 0.17 & Brown (10 YR 5/3) day loam; weak, fil 35.00 & 2250 & 42.50 & 8.00 & 0.85 & 14.50 & 3.26 & 3.34 & 0.58 & 280 & 174.00 \\
\hline 0023 & $17-39$ & Pale brown $(10$ YR $6 / 3)$ day loam; wei 38.00 & 19.50 & 42.50 & 8.30 & 0.86 & 15.81 & 3.51 & 3.52 & 0.62 & 3.50 & 158.00 \\
\hline 0023 & 39.42 & Yellowish brown (10 YR $5 / 4)$ sand; we 4.85 & 7.65 & 87.50 & 6.90 & 0.10 & 2.15 & 0.86 & 0.45 & & & \\
\hline .0023 & 42.96 & Yellowish brown $(10 \mathrm{YR} / / 4)$ sand; we 13.70 & 5.00 & 81.30 & 7.00 & 0.05 & 4.59 & 1.53 & 0.35 & 0.20 & 2.00 & 35.00 \\
\hline
\end{tabular}

Figure 3. The Description table.

stored in a binary text file. In Edaphology there are two modules for storing the data in the database. They are:

- Data preprocessing.

- Clustering and Dynamic decision tree construction.

\subsection{Data Pre-Processing}

Data preparation is the first step for converting the information obtained from Edaphologists to Quad tree format. 


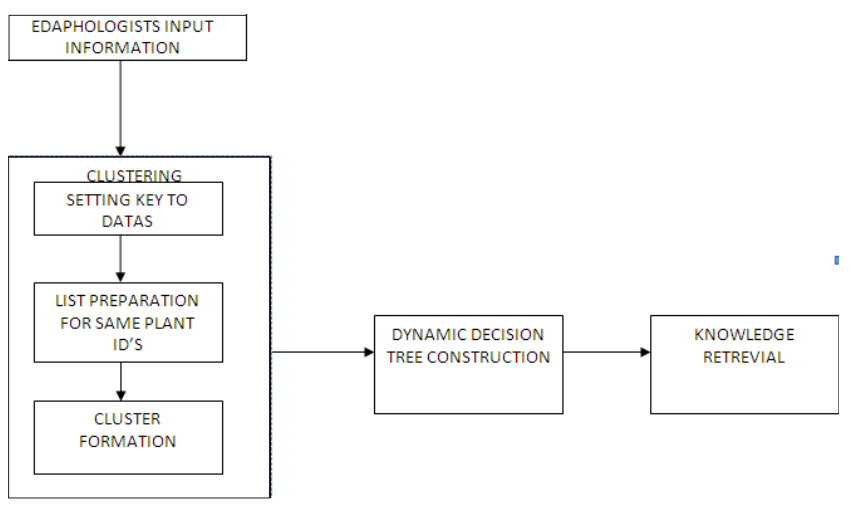

Figure 4. Data flow of the proposed work.

Table 1. Plant dataset

\begin{tabular}{|c|c|}
\hline Id & Id of the soil \\
\hline Name & Name of the soil \\
\hline Geology & Geological Value \\
\hline Taxonomy & Taxonomy structure of the plant \\
\hline
\end{tabular}

Table 2. Soil characteristics description

\begin{tabular}{|c|c|}
\hline Id & Id of the soil \\
\hline Depth & Depth of the Plant \\
\hline Desc1 & Description \\
\hline Clay & Clay level \\
\hline Silt & Silt value \\
\hline Sand & Sand Value \\
\hline $\mathrm{PH}$ & PH value \\
\hline $\mathrm{EC}$ & EC Value \\
\hline $\mathrm{Ca}$ & Calcium Content \\
\hline $\mathrm{Mg}$ & Magnesium Content \\
\hline $\mathrm{Na}$ & sodium Content \\
\hline $\mathrm{K}$ & Potassium \\
\hline
\end{tabular}

It involves two steps of type conversion and normalization. Here, initially the mean values of the attributes are computed and subsequently type converted and normalized. The description table consists of 17 soil features in which some are in the alphanumerical format. When the input is in the form of alphanumeric value, the system would not be able to access it; hence the value is converted to numeric values. The soil features are transformed to unsigned integer format.

\subsubsection{Type Conversion}

Categorical variables like soil color, strength and moisture are given in string format of multiple words like "light brownish grey". The categorical value is separated into a single word and every word is allocated a single byte. For every categorical variable, a lookup table is employed to substitute categorical values with numeric values. The conversion of the categorical data to numeric value is carried out as mentioned in the examples.

Example 1: "Light Brownish Grey" is coded as 00000001 $0000000100000001=2^{\wedge} 16+2^{\wedge} 8+2^{\wedge} 1$

Example 2: "Light Yellowish Brown" is coded as 0000 $00100000000100000010=2^{\wedge} 16+2^{\wedge} 9+2^{\wedge} 2$

Finally, the categorical values are transformed into numeric values in the respective columns and a $17-\mathrm{col}-$ umn vector each with numerical values is obtained.

\subsubsection{Normalization}

After type conversion, normalization is carried out to confine the values of diverse ranges to a defined specific range. Here, the values from all ranges are converted to a defined range of zero to one. After normalization, $7 \mathrm{col}-$ umn vectors (for 17 features of plant and soil) where each column value ranges between 0 and 1 are obtained. The normalization technique employed in this system is the min-max normalization technique which is used to have the feature values in the range of 0 to 1 .

The Pseudo code of the min-max normalization technique is given below:

$$
\begin{aligned}
& \text { For } i=1: N a \\
& \operatorname{Min}_{\text {old }}=\text { Find } \operatorname{Minimum}(i) \\
& \operatorname{Max}_{\text {old }}=\text { Find Minimum }(i) \\
& \quad N i=\left(\left(i-\operatorname{Min}_{\text {old }}\right) /\left(\operatorname{Max}_{\text {old }}-\operatorname{Min}_{\text {old }}\right)\right) \times\left(\operatorname{Max}_{\text {new }}-\operatorname{Min}_{\text {new }}\right)+\operatorname{Min}_{\text {new }}
\end{aligned}
$$

Where, Max ${ }_{\text {new }}$ - specified maximum value to be converted $M_{\text {in }}$ - specified minimum value to be converted

Max old - Original max value of the variable

$\mathrm{Min}_{\text {old }}$ - Original min value of the variable

$\mathrm{Ni}=$ Normalized values.

\subsection{Clustering and Dynamic Decision Tree Construction}

Generally clustering is the task of grouping a set of objects in such a way that objects in the same group are more similar to each other than to those in other groups. Here a list is prepared with the plant IDs and it is stored in separate structures. And for each set a key is set along with their characteristics values. 
Plant ID's $-\mathrm{P}_{1}, \mathrm{P}_{2}, \mathrm{P}_{3} \ldots \ldots \mathrm{P}_{\mathrm{n}}$

$\mathrm{Ph}$ set- corresponding $\mathrm{Ph}$ value + key

Depth set -corresponding depth value + key

The process undergoes pre-pruning of decision tree and hence the size of the decision tree will be very less and can fit into main memory. Further selection of attributes may reduce the size of the tree even better. The lists are formed for the unique plant id's.

$\mathrm{Ph}$ value 6.61 is for the plant id's $\mathrm{P}_{7}, \mathrm{P}_{24}, \mathrm{P}_{250}$

$\mathrm{Ph}$ value 7.52 is for the plant id's $\mathrm{P}_{2,} \mathrm{P}_{28,} \mathrm{P}_{29}$

$\mathrm{Ph}$ value 6.52 is for the plant id's $\mathrm{P}_{9,} \mathrm{P}_{3}, \mathrm{P}_{240}$

The plant ids are inserted into the list. These unique sets are identified using a formula,

$$
\begin{gathered}
\text { Current node } * 2+\mathrm{n} \\
\text { For } 0=0^{*} 2+1=1 \\
0^{*} 2+2=2 \\
\text { For } 1=1^{*} 2+1=3 \\
1^{*} 2+2=4
\end{gathered}
$$

As shown in Figure 5, Now the sets are $(1,2)$ and $(3,4)$. After that the dynamic decision tree is constructed for every set. The tree is stored in the form of binary text file which consists of the plant information and soil characteristics.

\subsection{Dynamic Decision Quad tree Construction}

Once the dynamic decision quad tree is constructed for storage the quad trees are then constructed as shown in Figure 6. The algorithm for the Dynamic decision Quad tree construction is given below.

\section{Algorithm for Constructing Dynamic decision quad Tree}

In the code some representations are made and are defined as:

pta - Point which is to be added into the tree.

noid - The node identification number.

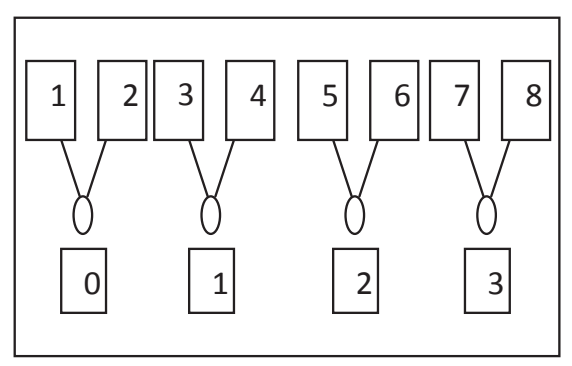

Figure 5. Key values for unique plant set.

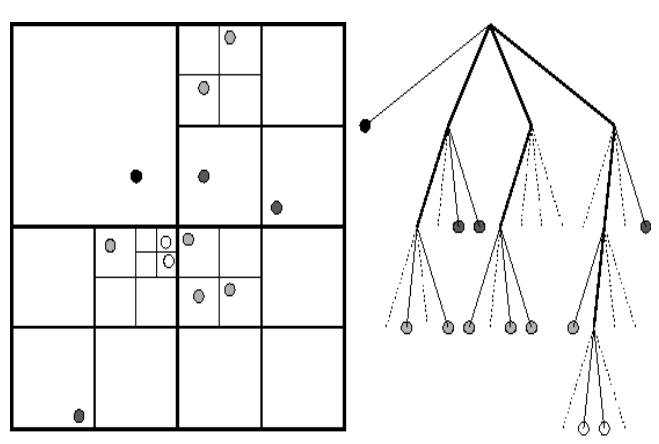

Figure 6. Representation of dynamic decision quad tree.

dis - The distance between node's coordinates and point's coordinates.

th - It represents the threshold value set to add a point to the node.

Flag $=0$;

Function add Point (point Pta)

While (! flag)

Noid $=$ searchnode $(p t$, Noid $)$

Dis $=\operatorname{distance}(p t$, Noid $)$

if (dis $>$ Th)

Splitnode(Noid)

Else

Addpoint node (pt, Noid)

Flag = 1;

End If

End While

\subsection{Retrieval of Plant Data}

From the constructed dynamic decision quad tree the plants names are retrieved and tested. In this paper, effective knowledge retrieval is carried out with the aid of XML architecture and XML tags. The system is designed for retrieving best plants for the input soil condition given by the user. When the user gives a query with input features, the suited plants are retrieved from the XML Quad tree. The information given by our system would benefit Edaphologists in knowing the right plants to be grown for the input soil conditions. That is right plant for the right soil characteristics are obtained with the aid of the system. The pseudo-codes for knowledge retrieval from XML and $\mathrm{XML}$ search are given below:

Function Search $x m l_{\text {element }}(p[], m i)$ $m x[4,2]$, Element Ele[4];

Element.El $=$ XML.GetElementByID $(\mathrm{mi})$

While (El.Getattribute(ital ISPARENT) $=1)$ nodule 
Ele[1] $=$ E11.NextChildElement(ital TopLeft)

Ele[2] = E12.NextChildElement(ital TopRight)

Ele[3] = E13.NextChildElement(ital BottomLeft)

Ele[4] $=$ E14.NextChildElement(ital BottomRight)

$m x[1,:]=$ El1.GetAttributes $(A, B)$

$m x[2,:]=$ El2.GetAttributes $(A, B)$

$m x[3,:]=$ El3.GetAttributes $(A, B)$

$m x[4,:]=$ El4.GetAttributes $(A, B)$

$i d=$ findnearest $_{\text {nodule }_{\text {id }}}(p t, m x)$

$m i=$ Ele [id]. GetAttribute(ital NID)

$E l=X m l . G e t E l e m e n t B y I D(m i)$

End While

Return mi

End function

\section{Results and Discussions}

The sample input query and its corresponding output is shown in Table 3. For analyzing the performance of the implemented system, six input queries are used as shown Table 4 and their outputs are analyzed. Table 5 shows the number of plants retrieved, computation time and memory usage for the sample input queries. Figure 7 shows the number of plants retrieved for our proposed method and for our previous methods. Figure 8 shows the computation time for our proposed method and previous methods and Figure 9 shows the memory usage by our

Table 3. Sample input query and its output

\begin{tabular}{|c|c|}
\hline Input Query & Output \\
\hline Depth: $0-18$ & Name: Palmyrah \\
Color: red & Geology: Granite \\
Sand: sandy clay loam & Taxonomy: Fine, mixed, \\
Strength: moderate & isohyperthermic, \\
medium sub angular & noncalcareous, Typic Rhodustalfs \\
blocky & \\
Moist: slightly sticky & \\
Pores: common pores & \\
Clay: 24.60 & \\
Silt: 15.2 & \\
Sand: 60.2 & \\
PH: 7.36 & \\
EC: 0.04 & \\
CA: 8.0 & \\
Mg: 1.5 & \\
Na: 0.68 & \\
K: 0.32 & \\
P2O5: 29.45 & \\
K2O: 228.00 & \\
\end{tabular}

Table 4. Input queries

\begin{tabular}{|c|c|c|}
\hline Query1 & Query2 & Query3 \\
\hline Depth $=26-52$ & Depth $=50-91$ & Depth $=13-33$ \\
\hline Color $=$ light grey to & $\begin{array}{c}\text { Color }=\text { brownish } \\
\text { vellow }\end{array}$ & Color $=$ reddish \\
\hline Sand = sandy clay & Sand = clay & Sand = sandy clay \\
\hline Strength $=$ medium & Strength $=$ medium & Strength $=$ medium \\
\hline $\begin{array}{c}\text { moderate sub angular } \\
\text { blocky }\end{array}$ & $\begin{array}{c}\text { moderate sub angular } \\
\text { blocky }\end{array}$ & $\begin{array}{c}\text { weak sub angular } \\
\text { blocky }\end{array}$ \\
\hline Moist $=$ sticky & Moist $=$ sticky & Moist = sticky \\
\hline Pores $=$ pores & Pores $=$ few pores & Pores $=$ few pores \\
\hline Clay = 36.31 & Clay $=38.89$ & Clay $=47.00$ \\
\hline Silt $=13.51$ & Silt $=20.25$ & Silt $=22.00$ \\
\hline Sand $=50.18$ & Sand $=50.18$ & Sand $=8.00$ \\
\hline $\mathrm{PH}=6.28$ & $\mathrm{PH}=8.65$ & $\mathrm{PH}=8.00$ \\
\hline $\mathrm{EC}=9.40$ & $\mathrm{EC}=0.09$ & $\mathrm{EC}=1.50$ \\
\hline $\mathrm{CA}=9.40$ & $\mathrm{CA}=15.34$ & $\mathrm{CA}=14.00$ \\
\hline $\mathrm{Mg}=1.80$ & $\mathrm{Mg}=7.82$ & $\mathrm{Mg}=10.00$ \\
\hline $\mathrm{Na}=0.50$ & $\mathrm{Na}=3.01$ & $\mathrm{Na}=1.10$ \\
\hline $\mathrm{K}=0.12$ & $\mathrm{~K}=0.12$ & $\mathrm{~K}=0.60$ \\
\hline $\mathrm{P} 2 \mathrm{O} 5=11.26$ & $\mathrm{P} 2 \mathrm{O} 5=14.00$ & $\mathrm{P} 2 \mathrm{O} 5=7.00$ \\
\hline $\mathrm{K} 2 \mathrm{O}=108.00$ & $\mathrm{~K} 2 \mathrm{O}=302.00$ & $\mathrm{~K} 2 \mathrm{O}=208.00$ \\
\hline Query4 & Query5 & Query6 \\
\hline Depth $=41-51$ & Depth $=23-37$ & Depth $=$ \\
\hline Color $=$ very pale brown & Color $=$ dark red & Color $=$ dark red \\
\hline Sand = sandy & Sand =sandy clay & Sand =sandy clay \\
\hline Strength $=$ medium sub & Strength $=$ moderate & Strength $=$ moderate \\
\hline $\begin{array}{c}\text { angular blocky } \\
\text { Moist = }\end{array}$ & $\begin{array}{l}\text { medium sub angular } \\
\text { blocky }\end{array}$ & $\begin{array}{c}\text { medium sub angular } \\
\text { blocky }\end{array}$ \\
\hline Pores $=$ & Moist $=$ slightly sticky & Moist $=$ slightly sticky \\
\hline Clay $=3.40$ & Pores $=$ few fine pores & Pores $=$ few fine pores \\
\hline Silt $=4.00$ & Clay $=40.00$ & Clay $=40.00$ \\
\hline Sand $=92.60$ & Silt $=24.00$ & Silt $=24.00$ \\
\hline $\mathrm{PH}=8.00$ & Sand $=36.00$ & Sand $=36.00$ \\
\hline $\mathrm{EC}=0.06$ & $\mathrm{PH}=7.17$ & $\mathrm{PH}=7.17$ \\
\hline $\mathrm{CA}=3.57$ & $\mathrm{EC}=0.16$ & $\mathrm{EC}=0.16$ \\
\hline $\mathrm{Mg}=0.51$ & $\mathrm{CA}=10.00$ & $\mathrm{CA}=10.00$ \\
\hline $\mathrm{Na}=0.25$ & $\mathrm{Mg}=4.50$ & $\mathrm{Mg}=4.50$ \\
\hline $\mathrm{K}=0.10$ & $\mathrm{Na}=1.28$ & $\mathrm{Na}=1.28$ \\
\hline $\mathrm{P} 2 \mathrm{O} 5=4.00$ & $K=0.93$ & $\mathrm{~K}=0.93$ \\
\hline \multirow[t]{2}{*}{$\mathrm{K} 2 \mathrm{O}=49.00$} & $\mathrm{P} 2 \mathrm{O} 5=25.65$ & $\mathrm{P} 2 \mathrm{O} 5=25.65$ \\
\hline & $\mathrm{K} 2 \mathrm{O}=195.00$ & $\mathrm{~K} 2 \mathrm{O}=195.00$ \\
\hline
\end{tabular}

Table 5. Plants retrieved and computation time for different queries

\begin{tabular}{|c|c|c|c|c|c|c|}
\hline $\begin{array}{c}\text { Performance } \\
\text { Metrics }\end{array}$ & $\begin{array}{l}\overrightarrow{\widehat{d}} \\
\vec{g}\end{array}$ & 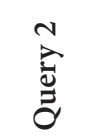 & $\overbrace{\bar{d}}^{\infty}$ & 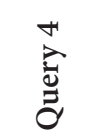 & 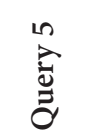 & 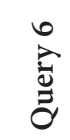 \\
\hline $\begin{array}{c}\text { Plants } \\
\text { Retrieved }\end{array}$ & 32 & 31 & 27 & 42 & 34 & 33 \\
\hline $\begin{array}{c}\text { Computation } \\
\text { time }(\mathrm{ms})\end{array}$ & 102 & 103 & 102 & 105 & 98 & 104 \\
\hline $\begin{array}{c}\text { Memory } \\
\text { usage }(k b)\end{array}$ & 2486 & 2487 & 2487 & 2487 & 2485 & 2486 \\
\hline
\end{tabular}




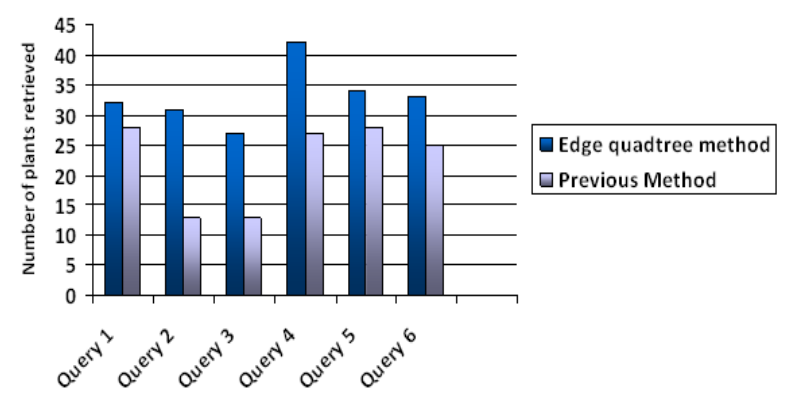

Figure 7. Chart showing the number of plants retrieved for various queries by the two methods.

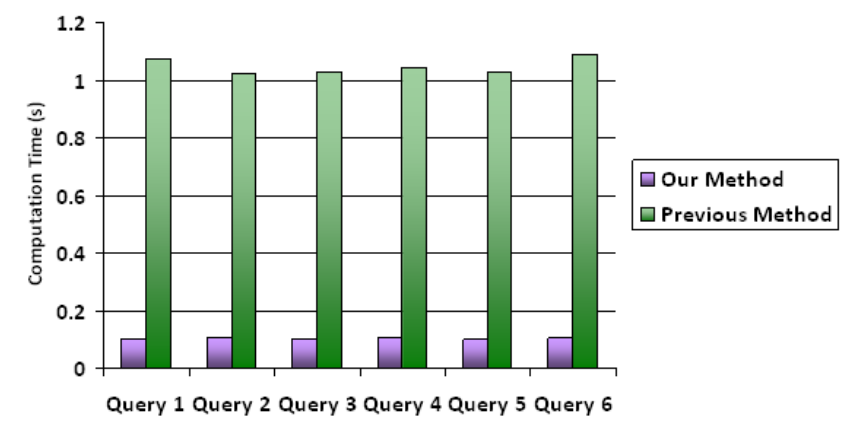

Figure 8 Chart showing the computation time for various queries by the two methods.

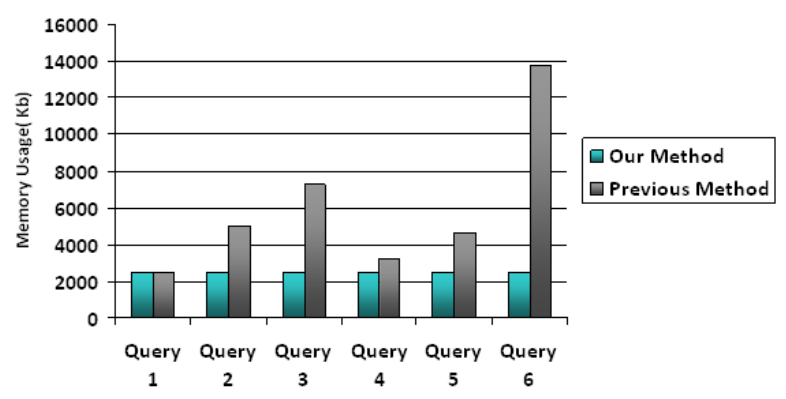

Figure 9. Chart showing the memory usage for various queries by the two methods.

proposed method and previous methods. It can be seen that an average of 33 plants are retrieved per user query. Maximum value came about 42 for 4 th query. The system consumed an average of $2486 \mathrm{~Kb}$ per query. Average computation time came about $102 \mathrm{~ms}$. High number of plants retrieved, low memory usage and low computation time further demonstrates the effectiveness of the system.

\section{Conclusion and Future Work}

Clustering and Dynamic decision tree technique is used in this work for storing data in edaphology. The proposed sys- tem proves better storage when compared to the previously existing systems. Here the storage is in the form of binary text file which reduces the memory space and allow more number of plants to be stored. This would help the Edaphologists and agriculturists in obtaining more appropriate results at the time of retrieval. Here, dynamic decision quad trees are used and better retrieval is achieved for various inputs.

The future scope of our work is to employ still better technique for storage and retrieval for getting relevant plant names. The new technique may be designed with the aim of retrieving more number of plants for the input soil characteristics and it should be with low memory usage and low computation time.

\section{References}

1. Ras E, Rech J. Using Wikis to support the Net in improving knowledge acquisition in capstone projects. International Journal of Systems and Software. 2009; 82(4):553-62.

2. Wang YJ, Xin Q, Coenen F. Hybrid Rule Ordering in Classification Association Rule Mining. International Journal of Transactions on Machine Learning and Knowledge Mining. 2008; 1(1); 1-15.

3. Egecioglu O, Ferhatosmanoglu H, Ogras U. Dimensionality reduction and similarity Computation by inner-product approximations. IEEE Transactions on Knowledge and Data Engineering. 2004; 16(6):714-26.

4. Ozbayrak M, Bell R. A knowledge-based decision support system for the management of parts and tools in FMS' International Journal of Decision Support Systems. 2003; 35(4):487-15.

5. Prasad R, Bihar ABR, Sinha AK. KISAN: An Expert System for Soil Nutrient Management. AFITA 2002: Asian agricultural information technology and management. Proceedings of the Third Asian Conference for Information Technology in Agriculture; Beijing: China. 2002. p. 26-28.

6. Denning S. The role of ICT's in knowledge management for development. The Courier ACP-EU; 2002. p. 58-61.

7. Wang Y, Wang J, Zhang S. Collaborative knowledge management by integrating knowledge modeling and workflow modeling. Proceedings of IEEE International Conference on Information Reuse and Integration; IRI'05; 2005. p. 13-18.

8. Chen SK. An Exact Closed-Form Formula for D-Dimensional Quadtree Decomposition of Arbitrary Hyperrectangles. IEEE Transactions on Knowledge and Data Engineering. 2006; 18(6): 784-98.

9. Sikder IU. Knowledge-based spatial decision support systems: An assessment of environmental adaptability of crops. Expert Systems with Applications: An International Journal. 2009; 36(3):5341-47. 
10. Abel M, Silva LAL, De Ros LF, Mastella LS, Campbell JA, Novello T. Petrographer: Managing peterographic data and knowledge using an intelligent database application. Expert systems with Application. 2004; 26(1): 9-18.

11. Bui EN, Henderson BL, Viergever K. Knowledge discovery from models of soil properties. Ecological- Modelling. 2006; 191(3-4): 431-46.
12. Faloutsos C, Jagadish HV, Manolopoulos Y. Analysis of the N-Dimensional Quadtree Decomposition For Arbitrary Hyperrectangles. IEEE Transactions on Knowledge and Data Engineering. 1997; 9(3):373-83.

13. Venkatesan E, Velmurugan T. Performance Analysis of Decision Tree Algorithms for Breast Cancer Classification. Indian Journal of Science and Technology. 2005; 8(29):1-8. 